\title{
The networking of alpine pastures for the development of sustainable tourism
}

\author{
M. P. Gatti \& G. Cacciaguerra \\ Department of Civil, Environmental and Mechanical Engineering, \\ Trento University, Italy
}

\begin{abstract}
Tourism is characterized by noteworthy changes regarding both the demand and the innovations in the services aimed to make the tourist experience more and more fulfilling and sustainable.

Today, tourists are interested in living the journey also as an opportunity to catch the cultural and social aspects of a place.

Summer pastures ("alpeggi") and seasonal alpine farmsteads ("malghe") are important spaces for tourism, but these are fundamental components of the economy, the society and the culture of the alpine landscape.

In this context, leading new congruent principles to the re-use and refunctionalisation of summer farmsteads ("malghe"), alpine huts ("baita") and all other seasonal production structures must be identified, in an attempt to valorise both traditional aspects and the innovative potentials of participated or nature tourism, able to guarantee the right environmental and economic sustainability. Keywords: alpine architecture, sustainability architecture, tourism, conservation and valoritation.
\end{abstract}

\section{Seasonal alpine buildings}

Summer pastures ("alpeggi") and seasonal alpine farmsteads ("malghe") are fundamental environmental, economic, social and cultural components of the alpine landscape, places where man and nature meet. They symbolise an environment unique for its complexity, diversity and high natural, environmental and cultural values. The areas occupied by the summer pastures also testify to the local typological, settlement, architectural and technological characteristics, just as those which developed on the valley floor where in many cases the settlement 
and architectural rules of the historic types have been partially cancelled by the globalisation which has standardised landscapes throughout Europe, creating the same buildings and the same spaces.

The seasonal use of land and buildings at high altitudes and in many cases their abandonment have avoided radical modifications and many of these elements have therefore come down to our time with no interruptions in the process of constructing and transforming the anthropic elements.

In many alpine areas, the design approach to recover or transform these buildings must be preceded by the indispensable interpretation of the evolutionary processes which guaranteed the environmental-ecological balance as a function of man's changing demands. A balance which must continue to regulate transformation of these alpine areas, fruit of dynamic modifications induced by the production system and the compatibility of the architectural characteristics with the environment and operational functionality.

As is well known, the morphology of these places is in constant evolution under the action of time and the climate (avalanches, snow slips, earthquakes, etc.) and changes in plant and animal species influence the architecture which varies according to man's needs. The themes of adaptation and transformation have therefore always been tackled in close synergy, despite the technologically modest solutions available. Through his productive, social and cultural activities, the capacity of contemporary man to transform is without doubt much greater, to the point of representing an abuse of power, cancelling out the heredity transmitted by previous generations.

The presence of man at high altitudes is still necessary today in order to govern the landscape and the land, but he must go back to following strategies appropriate to achieving transformation congruent with conservation in a context of constant valorisation.

The principle accepted by society as a whole is contained in Community documents. The first of these is without doubt the European Landscape Convention adopted by the European Council of Ministers Committee on 19 July 2000, accepted in Florence on 20 October the same year by the then signatories of the Treaty of Maastricht and today ratified by 37 European governments, including Italy (the European Landscape Convention was ratified by the Italian State on 4 May 2006, with validity from 1 September 2006).

The Convention is inspired by the need to encourage public authorities to adopt European landscape protection, management and planning policies compatible with sustainable development and able to reconcile social needs, economic activities and protection of the environment.

The articles of the Convention should be applied in all natural, rural, urban and periurban spaces. This therefore includes areas at the vegetation line whose characteristics derive from the action of natural and/or human factors and their interactions. Seen in these terms, defence and maintenance of summer pasture areas represent not just an opportunity for socio-economic development, but also satisfy the requirements for landscape quality, becoming in this sense everyone's right and responsibility in the spirit of the Convention, through participated decision-making processes integrating the landscape in land, urban planning, 
cultural, environmental, agricultural and socio-economic policies. The link existing between natural and anthropic elements of the landscape, the basis for the European level indications, is evident in the Cultural and Landscape Code (Italian Legislative Decree no. 42 of 22 January 2004).

According to this legislative document, alpine farmsteads and summer pastures must be considered as both cultural and landscape assets, therefore both artificial and natural. This regulation takes its importance to society as a whole as the basis for both the valorisation processes indicated and the necessary public (not private) fruition, to guarantee transmission and knowledge of the heritage they represent in order to promote cultural development. By attributing landscape, social, cultural and economic value to the alpine heritage, today's more aware society has assimilated the need for greater sensitivity and global multifunctional valorisation considering both the built elements and their natural surroundings.

It now seems necessary to reflect a moment, particularly on what has been done in recent times, and to review the criteria of the mass tourism policy which characterised the closing years of the last century, aimed at economic privilege with the construction of hotels of conspicuous dimensions, doubtless very profitable in the past but today in crisis, due precisely to deterioration of the delicate man-environment-settlement relationship they violated.

The search for a non-elitist tourism more respectful of that relationship must necessarily dialogue with the pre-existing rural heritage in order to safeguard man's presence in the mountains and the characteristic values of the man-production-environment bond.

New congruent principles must be identified leading to the re-use and refunctionalisation of summer farmsteads ("malghe"), alpine huts ("baita") and all other seasonal production structures, in an attempt to valorise both traditional aspects and the innovative potentials of participated or nature tourism, able to guarantee the right environmental and economic sustainability.

Aware congruent valorisation must necessarily begin with precise and meticulous gathering and interpretation of knowledge about each seasonal structure and its surroundings, pasture or meadow, on a small and large scale, as a necessary prerequisite to safeguarding the culture which generated it and, in this particular case, the dynamics which promoted and developed the use of summer pastures over the centuries in alpine areas. The studies must highlight the resources and potentials of alpine farmsteads in order to consider the activities to be associated with the traditional ones. The important potentials and possibilities for valorisation of these environments through sustainable measures are without doubt numerous, but there is a need for diversification based on local natural and cultural values.

A network must be created to integrate other activities in the alpine farmsteads of a given area so as to obtain perfect functional integration able to guarantee a good level of profitability. It is therefore important to achieve complete integrated conservation and valorisation of the alpine farmsteads present in the Trentino. This study thus analyses the legislation in force which should lead to the implementation of congruent conservation and valorisation policies, but which has actually produced not always positive and complete results. With the consequence 
that, apart from tourists, the human presence in the mountains has become ever more occasional and sporadic, leading to a loss of local natural, environmental and cultural values.

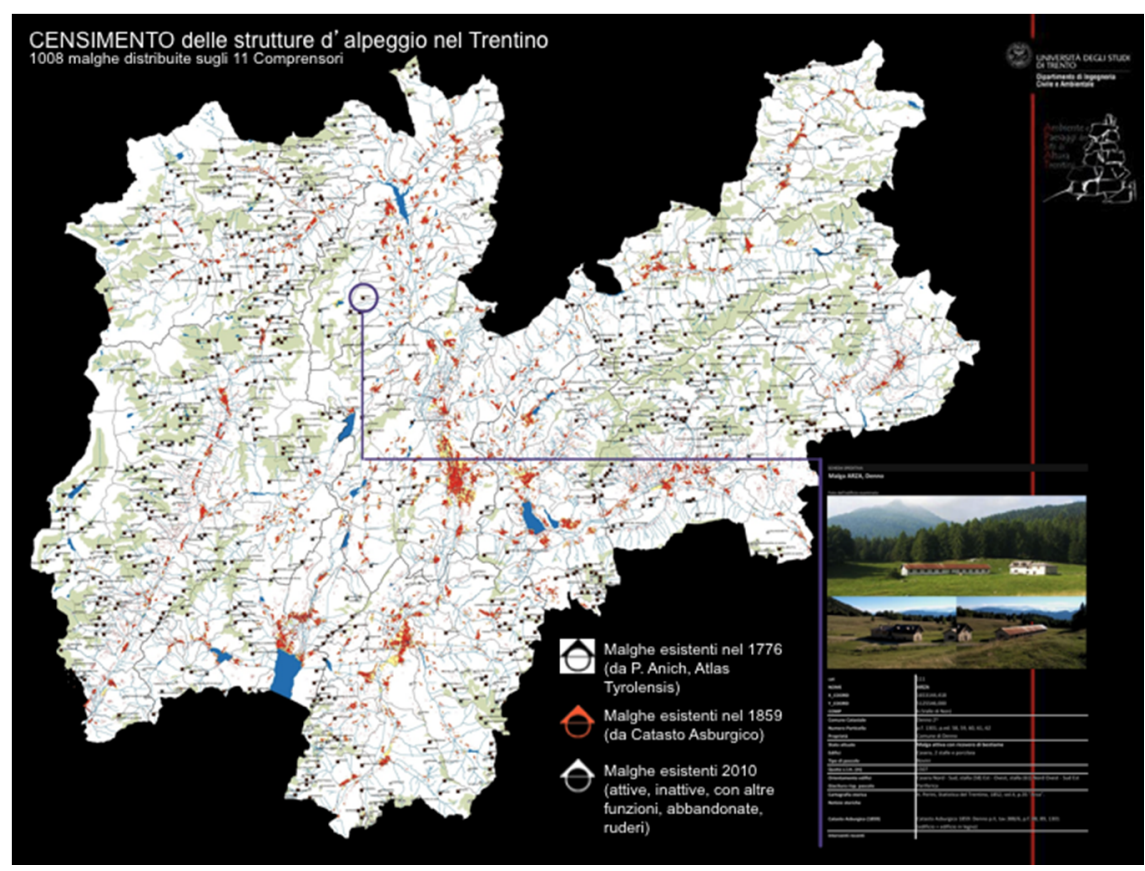

Figure 1: Farmsteads in the Trentino.

\section{The complex and variegated legislation in force}

From an initial analysis of the extensive legislation in force, it was immediately obvious that the legislation on seasonal alpine farmsteads at various levels always concerns individual aspects, in other words, it covers the buildings, or the surrounding production area, or technical matters associated with production of the products or management of the farmstead activities.

Even in areas where society has deep cultural and economic roots such as the Trentino, there is no organic legislation or ad hoc consolidating regulation on management of alpine pastures.

The guidelines for the use and management of mountain pastures were set out for the first time in Provincial Law no. 48 of 23 November 1978, abrogated by Regulation no. 11 of 23 May 2007, which proposed improving the efficiency and productivity of the Province's forests and encouraging utilisation of their resources for the benefit of the community as a whole, to raise the economic and social conditions of the mountain and improve ecological stability.

The legislation also covered alpine pastures and meadows, organising their management and defining their designated use and methods of utilisation through 
economic regulatory plans ("Piani di Assestamento"), drawn up at municipal level and by the public institutions running the alpine estates ("regole") in the high valleys. In the case of pastures, the law defined the areas to be used by livestock and these also served as a reference for the payment of contributions by the Autonomous Province of Trento Rural Development Plan which globally managed the financing of structural measures aimed at preserving the buildings as an integral part of the cultural heritage of the alpine environment. Current legislation, which abrogated the 2007 regulation, attributes maximum value to the sustainability of the transformations in order to improve stability of the physical factors of the area, the ecological balance of the forest and alpine environment and conservation of habitat and species biodiversity through balanced valorisation of the multi-functionality of the ecosystems.

The purpose of the law remains that of securing and consolidating all the factors contributing to creating the necessary conditions for man's continued presence in alpine areas. While in the 1978 regulation, hay meadows and summer pastures were treated only marginally, gaining importance only in municipal regulatory plans ("Piani di Assestamento"), in the new law, they became areas to be conserved and recovered to guarantee the multi-functionality of the natural ecosystems through regulation of artificial reforestation which prevents the creation of areas for the production of forage, the maintenance of footpaths and other measures for educational, promotional and valorisation purposes.

At both practical and legislative level, recovery of the alpine sites was promoted through the relaunch of economic activities associated with pastoralism and use of the summer pastures.

Provincial law no. 4 of 28 March 2003 supported the farming economy through the launch of organic farming and the control and accurate marking and certification of non-genetically modified products as niche products on the global food market.

With this provision, the alpine farmsteads once again occupied a central position for dairy and meat production, through an improvement in the living and working conditions and income of rural populations, the maintenance and sustainable development of farming activities and the safeguarding and valorisation of the environment of the rural alpine area with aid and special facilities for farms. The aim of the regulation was to preserve rural activities, foundation of the Trentino culture and vital to maintain a minimum level of population, preserving the alpine environment and safeguarding the available natural resources as a precondition for consolidation and development of other economic activities and the recovery and use of marginal resources.

The objective of these provisions was clearly to maintain a population living at high altitudes by guaranteeing a good income. The regulation set out to develop the activities of the alpine farmsteads by tackling themes such as the recovery of abandoned forage land, not compromised by the growth of trees or shrubs taller than two metres.

There was also a proposal for direct support of summer farmstead activities through a series of incentives, such as annual bonuses per hectare to compensate for the costs of utilising the summer pastures, or contributions to improve the 
pastures and alpine farmsteads for communal use and to implement all the measures and services necessary to guarantee or improve their management, including the relative infrastructure, by constructing access tracks and the water supply considered necessary for use by the farmsteads. The regulation aimed to promote pluralities in which the farming and animal rearing activities can be associated with rural tourism or cultural activities.

In this regard, the aim was to organise collective rural tourism, with rest and refreshment areas and accommodation at high altitudes, together with educational farms.

A further scope of the regulation was to implement collective improvement measures, such as improving the roads connecting the farmsteads.

Recent years have seen the issue of a large number of hygiene and sanitary regulations regarding dairy production, aiming at modernising valley floor and alpine dairy farms and bringing them into line with standards.

The first legal provisions covered mainly management of the alpine farmsteads and care of the pastures and the buildings in general for aspects regarding the conditions and health of the livestock, but all the laws passed during recent years are aimed at guaranteeing the hygiene and sanitary requisites of the cheese dairies annexed to the farmsteads and the milk processing structures in particular. The regulations have allowed restructuring of many seasonal alpine structures, introducing the possibility of selling products.

However, in the Trentino, in many cases the need to comply with hygiene and sanitary regulations actually led to abandonment, rather than restructuring, of the farmsteads. Despite the provision of contributions (mostly outright grants), restructuring of the farmsteads also necessitated modernising the water supply and wastewater treatment infrastructure and providing efficient electrical installations.

For example, the summer farmsteads were considered as equivalent to residential buildings, enforcing disposal of wastewater in cesspools or septic tanks and the transport of solid waste to dumps in the valleys. These provisions, fundamental to protect the integrity of the environment, in many cases blocked use of the structures, but subsequent regulations proposed more practicable solutions, developing the marketing of typical alpine products to keep the activity alive.

The need to conserve alpine activities and thus the structures has been evident since the early 19th century when "Agricultural Societies" ("Società Agrarie") were founded with the task of promoting more modern practices in the rural world, pressurising the municipalities or the institutions running the alpine estates ("regole") to set up community dairies in the valleys to process the milk, including that coming from the summer pastures, into products satisfying modern quality and hygiene requirements, transforming the job of cheese making, until then a home industry, into a more rational system in line with the new market demands.

The Hapsburg regulations were taken on board by the Italian government and improvements to the marketing of farm products continued, but conservation and valorisation was then largely transferred to the legal provisions of urban planning, issuing regulations on local area and individual building scale, often without considering the necessary integration and complementarity. 
The urban planning schemes approved to date (1968, 1987 and 2008) include precise guidelines for the recovery and valorisation of alpine farmsteads.

The latest planning tool includes general guidelines and criteria to regulate recovery of the alpine heritage, defining "...the conditions and operating methods to be adopted to conserve and valorise alpine structures in respect of traditional settlement and architectural models..." and safeguarding the environmental context. One of the objectives of the document is to draw up a census of all alpine architecture - alpine baite (huts) (cà da mont, bàit/o, fienile, tabià/tobià/tobiàdo, maso, masàdega), farmsteads, mills, forges and sawmills, even if abandoned or restored, structures outside towns and villages, whether in small groups or isolated at various altitudes in the mountains.

The document then proposes the in-depth study of existing structures, establishing the eligible types of building, the designated use and the possibility of reconstructing the layout of the complex, with precise operational guidelines covering sizes and construction technology.

This third planning level is becoming the most important tool for the comparison and validation of design choices as it identifies the existing heritage of alpine buildings to be restored, defining their conditions and the intervention methods in order to conserve and valorise them in respect of traditional local settlement and architectural models.

The guidelines and general criteria are aimed at safeguarding the environmental context. The admissible building operations must therefore be aimed at maintaining and recovering traditional alpine architecture and the relative agricultural and farming landscape, as the cultural and material testimony of the alpine civilisation, avoiding new urbanisation and modifications to the environment and landscape of the buildings and places.

Recovery of the buildings must always be aimed at safeguarding their environmental context.

The aim of this document is to arrive at a complete and structured overview of alpine farmsteads.

At present, only a few municipalities in the Province (generally those with the greatest tourism value) have drawn up and approved this document consisting of the census and regulations for implementation, but many other administrations still use the regulations contained in the urban planning schemes.

The Autonomous Province of Trento has also set up ecomuseums with the aim of achieving the valorisation of local culture and traditions, considering the possibility of combining the objectives of conservation and recovery of the traditional work environments with the material cultural heritage, thus linking the local styles of living and working to valorisation of buildings forming part of the local historical, artistic and popular heritage.

Connecting traditional landscapes with the reconstruction of traditional living and working environments able to produce goods and services, creating opportunities for marketing and selling local products.

In this context, the ecomuseum can represent "... a dynamic process with which communities conserve, interpret and valorise their heritage as a function of sustainable development, through a combination of itineraries designed to put 
visitors in contact with local nature, traditions and history, but above all with the active involvement of the communities, cultural organisations, schools and local associations which are the decisive and determining factor in a participated process which, through a pact (in other words, a dimension of shared values with extensive involvement of citizens in a consensual process), helps form the sentiment of identity which promotes positive social dynamics and improves the quality of life of residents. ...".

The last hundred years have seen definition of a complex body of regulations covering various themes associated with seasonal alpine structures and their immediate surroundings. While all of great interest, rather than promote the conservation and valorisation of the biodiversity of alpine ecosystems where nature and rural human activities have been intimately intertwined down the centuries, they all have sectorial objectives, penalising the more far-reaching project with a global vision of the landscape. Some of the regulations approved encourage and support conservation and valorisation of the farming and animal rearing economy, some environmental biodiversity, some the physical stability of the land, some the material culture, some history and others the aggregate and the building. This considerable and complex body of regulations in many ways penalises conservation and valorisation, or more precisely, it does not allow development of a more multidisciplinary vision which also considers the aspects of climate, fauna, economy, culture etc. This objective should be easy to pursue, thanks to the development plans approved for the alpine areas which include the protection of pastures with ecosustainable use, utilisation of production methods specifically aimed at conserving biodiversity and animal species, recovery of buildings, the construction of infrastructure, the provision of compensation for farmers in alpine areas, the development of farm tourism and direct sales in the alpine farmsteads of the products produced from the summer pastures, etc.

\section{Current guidelines and possibilities for valorising alpine farmsteads}

The objective of the current body of legislation with its numerous aspects appears to be environmental recovery and conservation of the biodiversity of the alpine ecosystems where nature and the rural activities of man have been intimately intertwined down the centuries.

On one hand, there is therefore a need to firstly introduce policies to protect the alpine systems, conserving their complexity and contrasting the reafforestation or desertification of pastures and meadows. Then the efficacy and compatibility of the safeguarding measures adopted to contrast the natural actions induced by abandonment must be verified in order to successfully design and plan measures for prevention, naturalisation and restoration of the ecosystems using bioengineering techniques to recover, develop and improve the rural techniques of the past. 


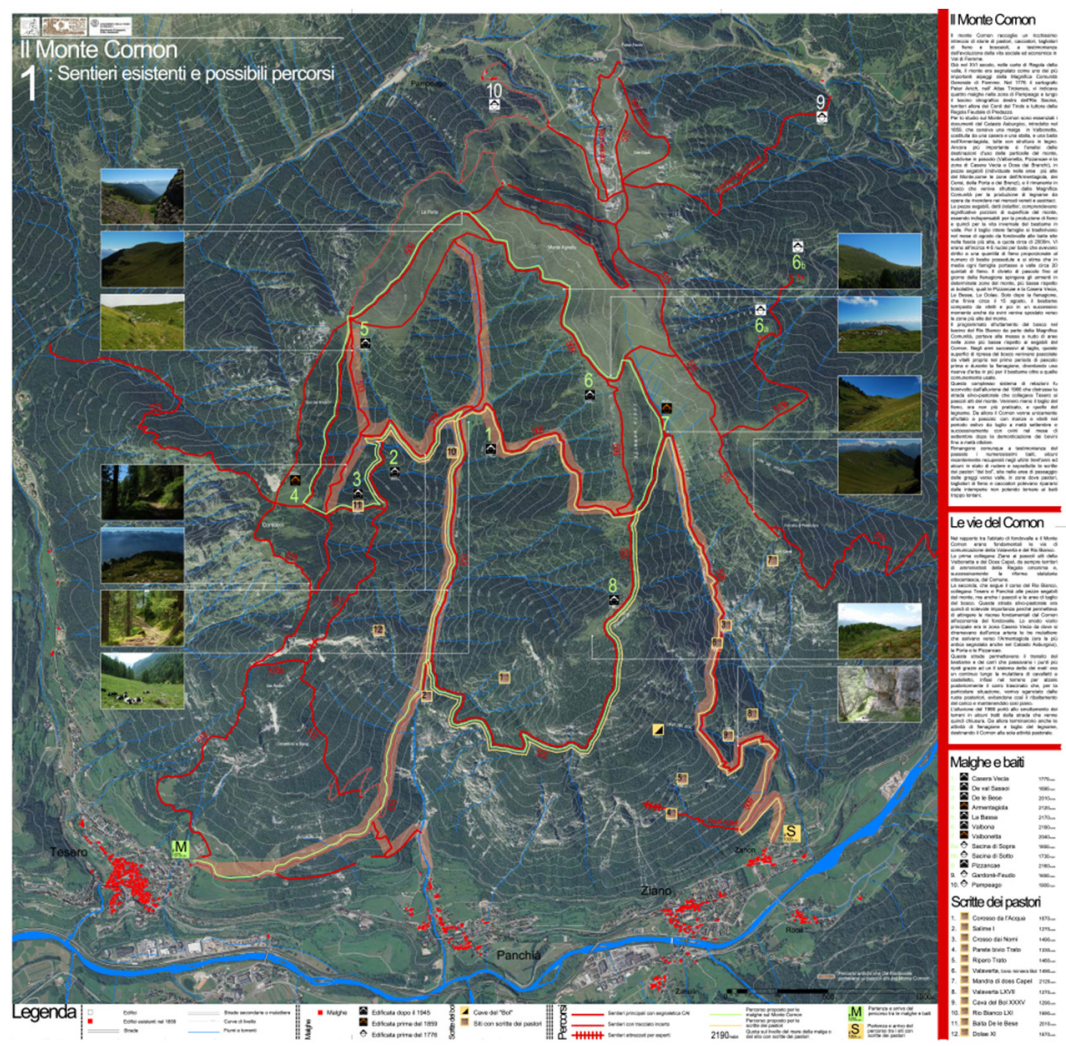

Figure 2: Valorisation of the alpine farmsteads in the Cornon valley.

The current state of the production buildings and pasture or meadow areas throughout the Trentino highlights a series of problems and criticalities which this vast body of regulations, from wide-area, landscape or local plans to municipal or sector schemes, has successfully resolved at sectorial level.

From the first crises hitting the alpine farmsteads in the 19th century due to overcrowding of the pastures and livestock disease, to the modern crisis after the Second World War induced by the net break between the modern world and the old rural world, the responses appear to be the same, with functional restructuring (sometimes distorting the typological characteristics) of the few alpine farmsteads still working and considered able to achieve a size and rational structure as part of a more modern production process according to the guidelines of the Provincial Urban Planning Scheme of 1968, and with recovery measures promoted by local associations and involving small structures with the objective of creating outposts and bivouacs at the service of both transhumant livestock farming and alpine tourism, encouraged with incentives by the subsequent Provincial Urban Planning Scheme of 1987.

Common to all the whole of the Trentino, these initial responses to the crisis among seasonal alpine farmsteads and forage production activities, leading to 
abandonment of the old seasonal settlements at high altitudes, have in part saved a world which the sudden changes in the economy and life in the valleys would otherwise have doubtless eliminated in a short space of time.

However, it must be emphasised that interventions involving existing alpine buildings and structures have only rarely been coordinated and in the majority of cases involve point intervention on individual structures only.

The result has been a strong expansion of woodland, causing simplification of the landscape, with a loss of the wood-clearing-meadow mosaic structure formerly characteristic of the Trentino Mountains and an overall reduction in the complexity of a series of environments to which a significant portion of the alpine biodiversity is linked.

It is evident that congruent conservation, valorisation and transformation requires an interdisciplinary operation based on overall knowledge of all the elements involved. This means that botanists, agronomists, geologists, urban planners, architects, economists etc. must work together with the same objective, contributing their knowledge without exceeding the bounds of their specific disciplines. To achieve this, it is particularly important to reunify the regulations on seasonal alpine farmsteads, considered as production units in which the landscape also includes built elements. An examination of the regulations and urban planning schemes existing to date seems, for example, to show an absence of guidelines on the immediate surroundings of the buildings as, for example, there are few regulations covering the arrangement and juxtaposition of the buildings, which limits the hypothesis of expansion. There is a need for provisions which provide incentives for construction, or for recovering existing structures, integrated with the typology of equivalent structures in the valley, without forgetting the material sustainability and energy self-sufficiency necessary in these outposts located in a difficult place which can be used for very brief periods only. The valorisation process must become the objective to be pursued in all possible recovery actions involving summer pastures and hay meadows, considered as both buildings and production area. It is fundamental to create a network within which to develop the area's tourism potential, together with rural activities and crafts for maintenance of the mountains. In this context, the stratification of buildings, seasonal farmsteads, alpine farms and huts ("malghe", "masi" and "baiti") in a limited area makes it necessary to differentiate their use in a pluralism of functions, not just productive, but also for accommodation, didactic and cultural purposes and as simple shelters in a defined or definable itinerary which, through various stages, leads to the discovery and dissemination of local historical and social themes, while at the same time contributing to forming a sense of identity among the population.

The basis for this process is knowledge of the structure undergoing restoration, taken as the starting point for a project for re-utilisation which must always be based on transmission of the material traces which document the transformations the structure has undergone over time, witness to the material culture which has produced them, in order to support the choices on the basis of a value judgement finalised at handing down the "knowledge" inherent in the built structure and re-establishing its potential unity. 
In the case of existing buildings, knowledge is therefore the fundamental aspect of the design process, necessary to effectively guide the choices for conserving and valorising the structure and defining guidelines applicable to alpine sites in the Trentino. In today's culture, ever greater importance is attributed to the past, because its values and its traditions can represent a basis for the future.

The aim is thus to avoid all the errors committed in the recent past when modernity seemed able to resolve all the issues of living and inhabiting, methodologically making a clear break between the "what was" of traditional architecture and building and the "what would be".

During the last two centuries, numerous interventions have been carried out on the built fabric and on a large scale also on the landscape. In many cases these have distorted the original characteristics of the Trentino valleys.

In this regard, the urban centres and valley floors in general have undergone the greatest transformations, not just in the dimensions of the built area, but also in the typological and construction characteristics. These characteristics are, on the other hand, better conserved in the areas, small towns and villages and built elements which, due to their peripheral position with regard to economic traffic, were abandoned during the second half of the 20th century.

In the current debate regarding the existing, the question (supported by cultural and economic considerations) is whether restoration makes sense, or whether it would be more appropriate to carefully and sustainably transform what has been abandoned in the valleys and which at present represents the last traces of a material culture which has now been lost.

Does it make sense to intervene where operations have already been proposed which would modify the plan and elevation to such an extent as to distort their characteristics, compromising the historical dignity of the existing built-fabric and transforming the structures using completely different settlement rules, or constructing architecture "unusual" for its size and style with respect to local tradition? In the Alps, abandonment of high altitude settlements is common to many valley areas, but after an initial phase involving the involuntary conservation of the buildings and their values, there is now a risk that they will disappear as a result of their non-transformation, above all in economic terms. The result has been an end to the seasonal maintenance necessary to preserve the unstable balance between anthropic development and nature which at these altitudes and in these particular climates is powerful enough to cancel out man's achievements over many centuries in just a few decades.

In the complex land use calibrated over the centuries to the subsistence of the population, the highest band in the valleys, above the forest cover on the mountainsides, played a fundamental role for grazing in the pastures and for logging activities in the meadows. These structures (farms and seasonal alpine farmsteads and huts), due to their peripheral position with respect to the valley system also those most affected by abandonment, were inserted in the territory congruently and compatibly in a way that would today be called sustainable. Cultural and economic values, together with those associated with land stability and integrity, make it necessary to implement conservation and valorisation policies, as in these we rediscover our past and our future. 
In light of these general design and planning policies, particular importance is attributed to re-utilisation, in other words, the functions to be given to the structures being recovered, which need not necessarily reflect the previous livestock farming use, but could go beyond to enter different spheres of activity, such as nature and sustainable tourism associated with trekking.

Today we face difficulties in achieving these objectives, although the intentions and directions of the extensive body of regulations on which our study is based are founded in valorisation of the existing.

Our research therefore analysed on one hand the areas and seasonal production settlements at the highest altitudes in a specific valley (the resulting considerations in reality are true for all alpine valleys), while on the other it examined the extensive body of regulations approved during the last fifty years in the building, tourism and animal farming sectors, including numerous provisions with the same objectives, but issued in different and often unconnected contexts, thus limiting its value and cancelling out its effectiveness.

The last part of the study focuses on research to acquire direct knowledge of the buildings and the characteristics and variations of the existing, because only carefully considered value judgements can guide the choices on what is most important to conserve the collective memory and improve economic and functional strategies.

\section{References}

[1] De Ros G., Baldessari E. \& Ventura W., I costi dell'alpeggio sono sostenibili? AaVv., Il sistema delle malghe alpine: aspetti agro-zootecnici, paesaggistici e turistici. San Michele all'Adige (TN): Società per lo studio e la valorizzazione dei sistemi zootecnici alpini, Quaderno Quaderni SoZooAlp nr.1, Udine, pp. 90-101, 2004.

[2] Finke, L., Introduzione all'ecologia del paesaggio. Traduzione italiana a cura di Rita Colantonio Venturelli, Franco Angeli, Milano, 1993.

[3] Cacciaguerra, G., Gatti, M.P. \& D’Ambros, GB. 2013; Le strutture temporanee del Cornòn: un insieme culturale ed economico. A c. Bazzanella, M. \& Kezich, G., Le scritte dei pastori: Etnoarcheologia della pastorizia in val di Fiemme, Sap, Mantova, pp. 175-210, 2013.

[4] Unione Europea, Quadro d'azione per uno sviluppo urbano sostenibile, 1999.

[5] Convenzione Europea del paesaggio, 20 October 2000, Firenze.

[6] Convenzione delle Alpi, 1991.

[7] Codice dei beni culturali e del paesaggio and d. Lgs. 24 marzo 2006 n. 156, d. Lgs. 24 marzo 2006 n. 15d. Lgd. 26 marzo 2008 n. 62, d. Lgd. 26 marzo 2008 n. 63

[8] Provincia Autonoma di Trento, Indirizzi e criteri generali per la pianificazione degli insediamenti storici, Provincia autonoma di Trento, Servizio urbanistica e tutela del paesaggio, Ufficio centri storici, Trento, 1999. 
[9] Provincia Autonoma di Trento, Indirizzi e criteri generali per a disciplina degli interventi di recupero del patrimonio edilizio montano, Provincia autonoma di Trento, Servizio urbanistica e tutela del paesaggio, Trento, 2008.

[10] Provincia Autonoma di Trento, Piano urbanistico provinciale. Relazione illustrativa, Centro duplicazioni della Provincia Autonoma di Trento, Trento, 2006.

[11] Provincia Autonoma di Trento, Documento preliminare, Elementi per la redazione del documento preliminare al fine dell'accordo-quadro di programma per l'adozione del piano territoriale della comunità (articolo 22 1.p. n. 1/2008), Assessorato all'Urbanistica, enti locali e personale, Trento, 2012.

[12] Provincia Autonoma di Trento, La revisione del Piano urbanistico provinciale: norme di attuazione, Provincia autonoma di Trento, Servizi dell'urbanistica, Tutela del paesaggio, Trento, 1984.

[13] Provincia Autonoma di Trento, 2000, Una nuova idea di territorio: riforma urbanistica e revisione del Piano urbanistico provinciale: documento di indirizzo, Temi, Trento, 2000.

[14] Aa.Vv. 1968, Il piano urbanistico provinciale, Quaderni, Il Trentino, nr. 89, Trento, 1968

[15] Provincia Autonoma di Trento, 1978, A dieci anni dal piano urbanistico provinciale, Provincia autonoma di Trento, Trento, 1978.

[16] Provincia Autonoma di Trento, 1962, Considerazioni sul piano urbanistico provinciale di Trento: relazione tenuta dal prof. Giuseppe Samonà al Convegno con architetti e ingegneri della provincia, Provincia autonoma di Trento, Trento, 1962.

[17] a c. F. Mancuso, L'urbanistica del territorio: il nuovo piano urbanistico del Trentino, Provincia autonoma di Trento, Marsilio, Venezia, 1991.

[18] B. Kessler, Il piano urbanistico provinciale come scelta e come elemento di equilibrio, Saturnia, Trento, 1996.

[19] E. Ferrari, I centri storici: una proposta di lettura degli antichi aggregati minori, Temi, Trento, 1980.

[20] C. Alexander, Note sulla sintesi della forma, traduzione S. Los, Il Saggiatore, Milano, 1967.

[21] E. Ferrari, I centri storici del Trentino, Servizi della urbanistica, Assessorato al territorio della Provincia Autonoma di Trento, Silvana, Isernia, 1981.

[22] B. Zanon, Centri storici minori e paesaggio antropico in Trentino, in Rassegna di studi e ricerche del dipartimento di scienze del Territorio del Politecnico di Milano, Milano. nr. 13, December 1992, pp. 51-61, Milano 1992.

[23] Aa.Vv, Indirizzi e criteri generali per la pianificazione degli insediamenti storici, Provincia autonoma di Trento. Dipartimento territorio, ambiente e foreste. Servizio urbanistica e tutela del paesaggio. Ufficio centri storici, Trento, 1993. 